\title{
A Comprehensive Method for Concrete Mix Design
}

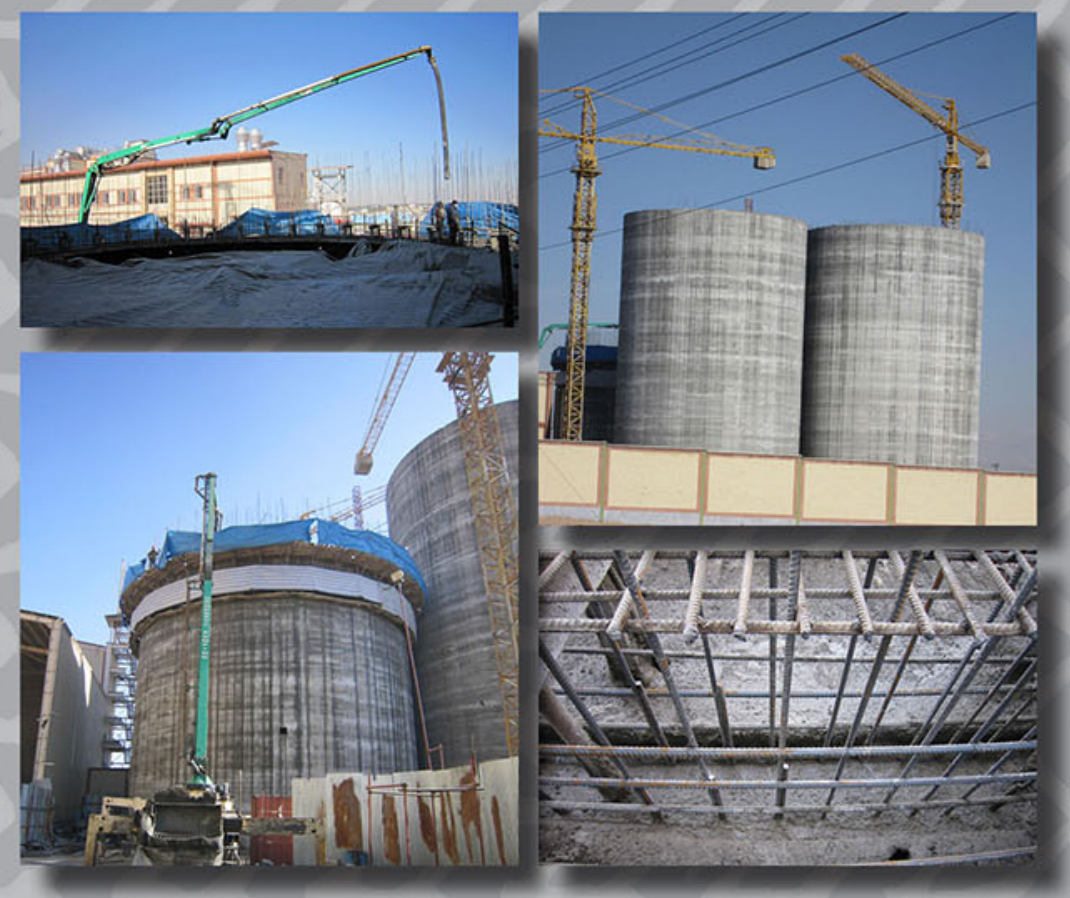

Kambiz Janamian

$$
\text { Jose Aguiar }
$$

\section{$M|R| F$}




\title{
A Comprehensive Method for Concrete Mix Design
}

Author

Kambiz Janamian

\author{
Co-author \\ Jose Aguiar
}

I dedicate this to:

my beloved wife Parinaz, the best participant in my life, and my little son 
Copyright (C) 2020 by the author

Published by Materials Research Forum LLC

Millersville, PA 17551, USA

All rights reserved. No part of the contents of this book may be reproduced or transmitted in any form or by any means without the written permission of the publisher.

Published as part of the book series

\section{Materials Research Foundations}

Volume 65 (2020)

ISSN 2471-8890 (Print)

ISSN 2471-8904 (Online)

Print ISBN 978-1-64490-058-1

ePDF ISBN 978-1-64490-059-8

This book contains information obtained from authentic and highly regarded sources. Reasonable efforts have been made to publish reliable data and information, but the author and publisher cannot assume responsibility for the validity of all materials or the consequences of their use. The authors and publishers have attempted to trace the copyright holders of all material reproduced in this publication and apologize to copyright holders if permission to publish in this form has not been obtained. If any copyright material has not been acknowledged please write and let us know so we may rectify in any future reprint.

Distributed worldwide by

\section{Materials Research Forum LLC}

105 Springdale Lane

Millersville, PA 17551

USA

http://www.mrforum.com

Printed in the United States of America

10987654321 


\section{Table of Contents}

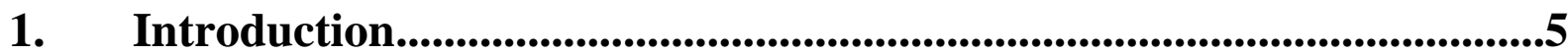

2. Concrete constituent materials specification ..............................................6

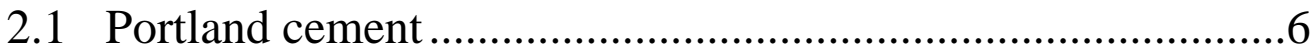

2.1.1Cements for our mix design check .........................................8

2.2 Other binders (Supplementary cementitious

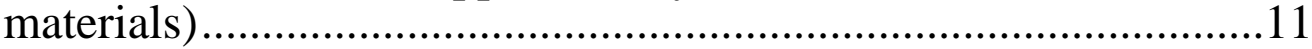

2.2.1Silica Fume ...................................................................12

2.2.2Ground Granulated Blast Furnace Slag (GGBS) ..................13

2.2.3Fly Ash ...........................................................................13

2.2.4Natural Pozzolans ...............................................................13

2.2.5Blended Cement ....................................................................14

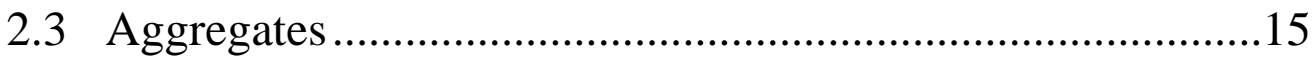

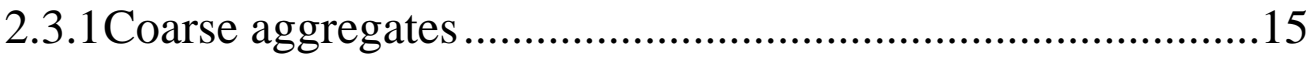

2.3.2Choosing maximum size of coarse aggregate ........................16

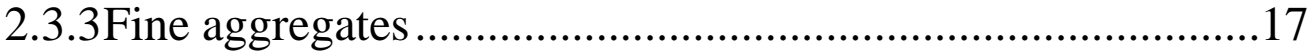

2.3.4Aggregates for our mix design check..................................17

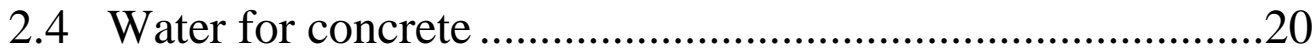

2.5 Chemical admixtures ........................................................21

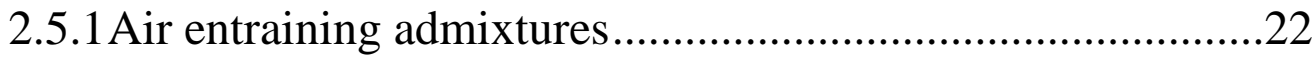

2.5.2Plasticizers and super-plasticizers ....................................22

2.5.3The novel test for obtaining water reduction rate of any plasticizer or super-plasticizer using cement mortar ..............23

2.5.4Super-plasticizer for mix design check ...............................24

2.5.3Control the water reduction rate for concrete.......................27

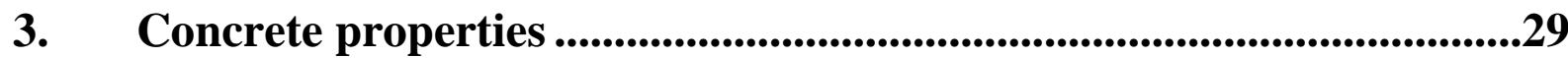

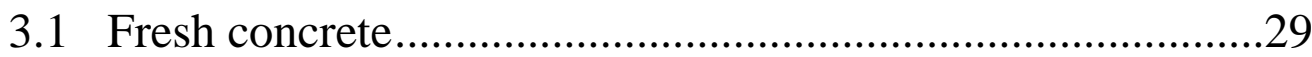

3.2 Control the temperature of fresh concrete.............................30

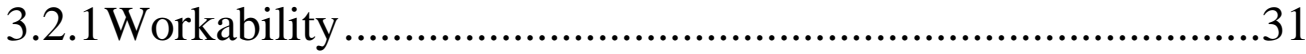

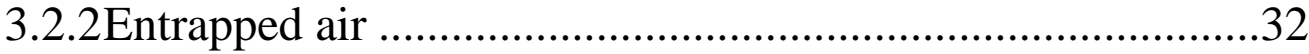

3.3 Hardened concrete ...........................................................33

3.3.1Concrete compressive strength test .....................................33

3.3.2Permeability of concrete....................................................35

4. The novel step by step procedure for the concrete mix design ............36

4.1 Goals of the concrete mix design .........................................36

4.2 Step (1): Specify standard deviation ....................................36 
4.2.1First method for standard deviation: Calculation from previous information .......................................................................36

4.2.2Second method for standard deviation ......................................37

4.3 Step (2): Specify mix design compressive strength ................38

4.4 Step (3): Specify percentage of each aggregate in the concrete

4.5 Step (4): Specify fineness module of total aggregates ...........39

4.6 Step (5): Specify water to binder ratio ....................................40

4.7 Step (6): Specify free water in concrete ..................................42

4.7.1Using plasticizers and super-plasticizers and their effect in free water

4.8 Step (7): Specify the amount of cement and other binders

4.9 Step (8): Specify the total volume of aggregates in concrete

4.10 Step (9): Calculating the weight of aggregates in saturated surface dry (SSD) condition

4.11 Step (10): Calculating the real weight of aggregates

and water in concrete

4.12 Making trial mix and control the specification for fresh and hardened concrete...............................................................46

5. Implementing mix design for a sample ready mixed plant ...................47

5.1 Specification of the ready mixed plant.....................................48

5.2 Different kinds of concrete in the ready mixed plant.............49

5.3 Calculations for concrete mix design ......................................50

5.3.1Step (1): Specify standard deviation ........................................50

5.3.2Step (2): Specify mix design compressive strength ...............51

5.3.3Step (3): Specify percent of each aggregate in the concrete 52

5.3.4Step (4): Specify fineness module of total aggregates ...........56

5.3.5Step (5): Specify water to binder ratio .....................................57

5.3.6Step (6): Specify free water in concrete ..................................59

5.3.6.1 Using of super-plasticizer .....................................................61

3.5.7Step (7): Specify the amount of cement and other binders

5.3.8Step (8): Specify the total volume of aggregates in concrete 
5.3.9Step (9): Calculating the weight of aggregates in saturated surface dry (SSD) condition

5.3.10 Step (10): Calculating the real weight of aggregates and water in the concrete

5.3.11 Final mix design sheets...................................................90

6. Confirmation tests for mix designs ..................................................131

6.1 Laboratory tests for mix design control ............................131

6.1.1Laboratory trials results..................................................133

6.2 Plant tests for checking concrete mix design ......................146

6.2.1Test results for plant ......................................................146

6.2.3Batching plant testing analysis ........................................159

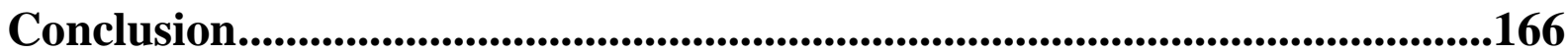

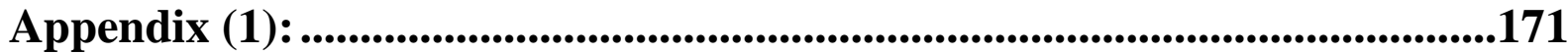

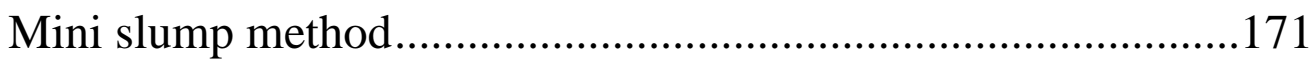

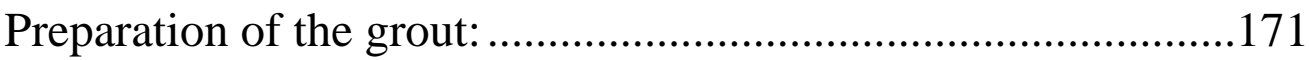

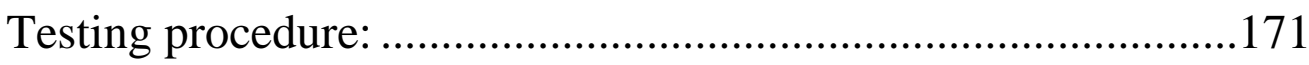

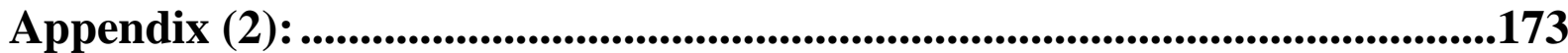

Marsh cone test ....................................................................173

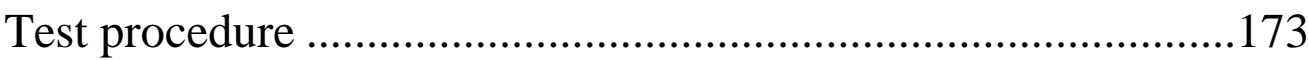

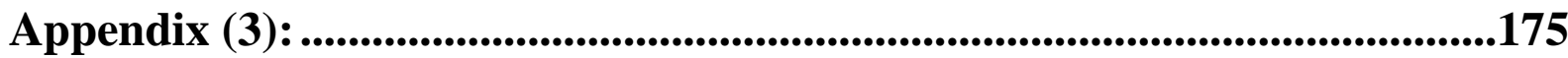

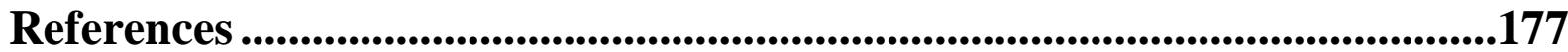

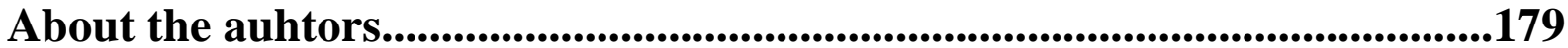

